\title{
Echa uprzedzeń: historyczne zbieżności w brytyjskiej postawie wobec żydowskich i muzułmańskich uchodźców ${ }^{2}$
}

Istotną część brytyjskiej mitologii narodowej stanowi idea, według której Wielka Brytania miała być miejscem schronienia dla uciekających przed wojną i prześladowaniami: od francuskich Hugenotów w XVII wieku, przez Polaków w czasie II wojny światowej, po Hindusów z Ugandy w latach 70. Ta idea brytyjskiej gościnności wydaje się jednak sprzeczna z obecnie rozpowszechnioną niechęcią do przyjmowania uchodźców. Dysonans ten możemy tłumaczyć tym, że pamięć zbiorowa nierzadko zaprzecza faktom: w historii każda fala uchodźców spotykała się z niezadowoleniem i wrogością, gdy docierała do brytyjskich brzegów.

Taką tendencję dobrze ilustrują zbieżności pomiędzy brytyjskimi reakcjami wobec dwóch grup uchodźców, które przybyły do Wielkiej Brytanii w odstępie stu lat. Pierwsza grupa to Żydzi, którzy docierali na Wyspy Brytyjskie w latach 1880-1940, uciekając przed pogromami w Rosji i prześladowaniami nazistowskimi. Drugą grupą są Muzułmanie, przybywający na Wyspy w ciągu ostatnich dwóch dekad. Pojawienie się obu grup stawało się źródłem tych samych obaw: przed obcością kultury i religii, która miałaby stanowić zagrożenie dla brytyjskich zwyczajów; przed rozprzestrzenianiem się radykalnych, agresywnych ideologii; oraz przed tym, że nowi przybysze będą konkurencją ekonomiczną dla mieszkańców.

Niniejsza praca poświęcona będzie podobieństwom i różnicom w brytyjskim dyskursie na temat żydowskich i muzułmańskich uchodźców, a także spróbuje zestawić te zbieżności i kontrasty z mitem gościnności uznawanej przez wielu Brytyjczyków za ich narodową cechę.

Słowa kluczowe: uchodźcy, Żydzi, Muzułmanie, antysemityzm, islamofobia, Wielka Brytania, historia, dyskurs

${ }^{1}$ Adres e-mail: daniel.tilles.2007@live.rhul.ac.uk. Adres do korespondencji: Uniwersytet Pedagogiczny im. Komisji Edukacji Narodowej, Filologia angielska, 31-128 Kraków, ul. Karmelicka 41, pok. 310. Telefon kontaktowy: (012) 6626201.

${ }^{2}$ Chciałbym podziękować osobom, które pomogły w tłumaczeniu tego artykułu na język polski: doktorowi Damianowi Podleśnemu, Annie Tilles oraz moim studentom z Uniwersytetu Pedagogicznego - jest ich zbyt wielu, by wymienić każdego osobno. 


\section{Echoes of Prejudice: Historical Parallels in British Discourse on Jewish and Muslim Refugees}

A prominent part of Britain's national mythology is the idea that the country has, throughout its modern history, provided refuge to those fleeing war and persecution around the globe. Yet this perception of hospitality as an historical British trait sits dissonantly alongside a widespread reluctance to accept today's refugees. This is because, as so often, collective memory contradicts historical fact: each wave of refugees has actually faced strong opposition to their arrival, and hostility once they reach Britain.

This pattern is well illustrated by the parallels between British reactions to two groups of refugees that arrived a century apart from one another: Jews, who migrated in large numbers in the period 1880-1940, fleeing first Russian pogroms and later Nazi persecution; and Muslims, who have come in the last two decades. Both have aroused many of the same concerns: that their alien culture and religion represents a threat to Britain's way of life; that they are responsible for spreading radical, violent ideologies which threaten British security; and that they would be an economic burden on the state and compete with the native population for resources.

This paper will explore the similarities - and differences - between British discourses regarding Jewish and Muslim refugees, and use these to reflect upon Britain's self-perceived national trait of hospitality.

Keywords: refugees, Jews, Muslims, antisemitism, Islamophobia, Britain, history, discourse

\section{Mit brytyjskiej gościnności}

Istotną część brytyjskiej mitologii narodowej stanowi idea, według której Wielka Brytania jest miejscem schronienia dla uciekających przed wojną i prześladowaniami: od 50 tysięcy protestanckich Hugenotów opuszczających katolicką Francję w XVII wieku, przez 250 tysięcy Belgów w czasie I wojny światowej i podobną liczbę Polaków w czasie drugiej, po dziesiątki tysięcy Hindusów wydalonych z Ugandy przez Idiego Amina w latach 70. XX wieku.

Ta koncepcja pojawia się regularnie w pracach historyków takich jak Bernard Porter, który pisze o brytyjskiej „długoletniej tradycji (...) [przyjmowania] uchodźców przed politycznymi tyraniami i ubóstwem, zapoczątkowanej w XVII wieku i trwającej do dzis'”3. Przywoływana jest ona przez organizacje lobbujące na rzecz uchodźców, takie jak Brytyjska Rada Uchodźców, której przedstawiciele twierdzą, że „ludzie starający się o azyl uciekają przed wojną, torturami i prześladowaniami i przybywają do Wielkiej Brytanii w poszukiwaniu bezpieczeństwa (...) [Powinniśmy] szanować historię Wielkiej Brytanii jako miejsca azylu dla prześladowanych"4. Są to również słowa często powtarzane przez samych uchodźców. Zygmund Freud,

${ }^{3}$ B. Porter (2013), Why the new British citizenship test distorts history, „The Guardian”, www. theguardian.com/culture/2013/jan/30/british-citizenship-test-distorts-history [data dostępu: sierpień 2017].

${ }^{4}$ Refugee Council (2010), Party leaders agree on importance of refugee protection, Refugee Council, www.refugeecouncil.org.uk/latest/news/837_party_leaders_agree_on_importance_of_refugee_protection [data dostępu: sierpień 2017]. 
który uciekł z Wiednia do Londynu po aneksji Austrii przez nazistów, napisał, że „wspaniała, wolna i łaskawa Anglia, w której teraz mieszkam, przyjęła mnie $\mathrm{z}$ otwartymi ramionami i traktuje jak mile widzianego gościa”.

Ten aspekt historii Wielkiej Brytanii jest używany dla poparcia poglądu Brytyjczyków o sobie jako narodzie tolerancyjnym, otwartym i gościnnym. W niedawno przeprowadzonej wśród Brytyjczyków ankiecie na temat najlepszych cech narodu „życzliwość" i „tolerancja dla wszystkich grup społecznych” znalazły się na drugim i trzecim miejscu najbardziej popularnych odpowiedzi ${ }^{6}$. Taki sposób postrzegania się ma tam długie korzenie. Siedemdziesiąt pięć lat temu George Orwell wspominał o „niezrównanej łagodności (...) Anglików (...) [której] nigdy nie zachwiał żaden Hymn Nienawiści”?.

Ta powszechnie uznana idea brytyjskiej gościnności wydaje się jednak sprzeczna z obecnie rozpowszechnioną niechęcią do przyjmowania uchodźców. Dysonans ten możemy tłumaczyć tym, że pamięć zbiorowa nierzadko zaprzecza faktom: w rzeczywistości każda fala uchodźców spotykała się z silnym sprzeciwem wobec swojego przybycia i wrogością, gdy dotarła do Wielkiej Brytanii. Zostało to już zapomniane przez współczesnych Brytyjczyków, którzy tak wychwalają historyczną, a naprawdę nigdy nieistniejącą gościnność i którzy w ogóle nie wywiązują się ze owej domniemanej gościnności w stosunku do dzisiejszych uchodźców.

Ta sprzeczność pomiędzy mitem a rzeczywistością zaczęła być zauważana w latach 70. i 80. XX wieku przez nową grupę uczonych, którzy po raz pierwszy potraktowali historię imigracji do Wielkiej Brytanii jako osobny temat zasługujący na uwagę ze stony środowiska naukowego. W artykule pt. Mit sprawiedliwości Colin Holmes twierdzi, że nadszedł czas, aby uznać, że choć Wielka Brytania była być może bardziej tolerancyjna niż inne kraje, to w jej historii istniały „okresy przemocy oraz powszechna wrogość w stosunku do mniejszości”. ${ }^{8}$ William Fishman posunął się jeszcze dalej, pisząc: „Wielu naszych kronikarzy przedstawia Wielką Brytanię jako otwarte społeczeństwo, $\mathrm{z}$ historycznego punktu widzenia schronienie dla uchodźców uciekających przed gospodarczym i politycznym uciskiem, których ogólnie traktowaliśmy z liberalną tolerancją (...) [Jednakże] rzeczywiste reakcje na imigranckich „najeźdźców” (...) rozwiewają te złudzenia. (...) Te „uroczyste mity” dawnej tolerancji brytyjskiej [muszą] odejść do historii”"

${ }^{5}$ S. Freud (1939), Moses and Monotheism (tłum. K. Jones), Londyn: Hogarth Press, s. 93.

${ }^{6}$ Ipsos Mori (2012), Britons are more proud of their history, NHS and army than the Royal Family, Ipsos MORI, www.ipsos-mori.com/researchpublications/researcharchive/2939/Britonsare-more-proud-of-their-history-NHS-and-army-than-the-Royal-Family.aspx [data dostępu: sierpień 2017].

7 G. Orwell (1941), England Your England, w: Orwell G., The Lion and the Unicorn: Socialism and the English Genius, Londyn: Secker \& Warburg.

${ }^{8}$ C. Homes (1985), The Myth of Fairness: Racial Violence in Britain, 1911-19, „History Today”, nr 35, s. 41-45.

9 W. Fishman (1992), Pride and Prejudice, „History Today”, nr 42, s. 60. 
Tony Kushner napisał niedawno wiele na ten temat $\mathrm{z}$ konkretnego punktu widzenia brytyjskiej historii przyjmowania uchodźców. We wspólnej książce z Katherine Knox, podobnie jak Fishman, kwestionuje on to, co opisuje jako „głęboko zakorzeniony mit brytyjskiej przyzwoitości i tolerancji”, który opiera się na „zadowoleniu z siebie oraz skłonności do samogratulacji”. Brytyjczycy wolą „nieskomplikowaną (...) uroczystą historię (...) ze szczęśliwym zakończeniem", a nie stawianie sobie trudnych pytań, na które odpowiedzi mogą być niewygodne ${ }^{10}$.

Ponadto zdaniem Kushnera ta postawa niesie za sobą pewne skutki. Ponieważ Brytyjczycy stworzyli wyidealizowany obraz uchodźców w przeszłości, obecni imigranci, którzy okazali się osobami niespełniającymi ich oczekiwań, niejednokrotnie spotykają się z wrogością. Według Kushnera „[Brytyjczycy] twierdzą, że państwo powinno [dać] azyl tym, którzy $\mathrm{w}$ istocie go potrzebują, a tacy są ich zdaniem reliktem przeszłości”"11. Co więcej, Wielka Brytania wykorzystuje tę wykreowaną historię, aby wypierać się winy za obecną niechęć w przyjmowaniu uchodźców. Biorąc pod uwagę to, za jak gościnnych i tolerancyjnych (od zawsze) uważają się Brytyjczycy, jakiekolwiek problemy, które uchodźcy napotykają na swojej drodze, muszą być winą ich samych, a nie dobrodusznych Brytyjczyków. Jak pisze historyk Louis London: „Ten wygodny sposób postrzegania uchodźców zapisał się na trwałe w umysłach Brytyjczyków i jest nadal przytaczany w celu potwierdzenia, że zawsze $\mathrm{z}$ chęcią przyjmowali imigrantów. Ostatnie surowe środki zapobiegawcze tłumaczą z kolei chęcią oddzielenia prawdziwych uchodźców od oszustów"12.

Brytyjczycy, nie wyciągając wniosków z przeszłości, ponownie wykazują się postawą pełną uprzedzeń względem każdej grupy uchodźców. Jeden z badaczy, Panikos Panayi, również to zauważył, twierdząc, iż „Wszystkie grupy imigrantów pojawiające się w Wielkiej Brytanii przez ostatnie dwieście lat spotykały się z rasizmem i ksenofobią zarówno ze strony rządzących, jak i samego społeczeństwa (...). Choć główna grupa ofiar zmieniła się, rodzaj niechęci pozostał taki sam”13.

\section{Uchodźcy żydowscy i muzułmanie}

Zależność tę dobrze widać na przykładzie podobieństwa w reakcjach Brytyjczyków na przybycie dwóch różnych grup uchodźców, które pojawiły się na Wyspach Brytyjskich w odstępie jednego stulecia. Pierwszą z nich stanowili Żydzi,

${ }_{10}$ T. Kushner, K. Knox (1999), Refugees in an Age of Genocide: Global, National and Local Perspectives During the Twentieth Century, Londyn: Routledge, s. 310, 403, 410.

11 A. Karpf (2002), We've been here before, „The Guardian”, www.theguardian.com/uk/2002/ jun/08/immigration.immigrationandpublicservices [data dostępu: sierpień 2017].

12 L. London (2000), Whitehall and the Jews, 1933-1948: British Immigration Policy and the Holocaust, Londyn: Cambridge University Press, s. 13.

${ }^{13}$ P. Panayi (2010), An Immigration History of Modern Britain: Multicultural Racism Since 1800, Londyn: Routledge, s. 318. 
którzy licznie przybywali do Wielkiej Brytanii od końca XIX aż do połowy XX wieku, uciekając przed prześladowaniami i pogromami w carskiej Rosji, a później w okupowanej przez nazistów Europie. Druga fala uchodźców to muzułmanie, którzy w ostatnich latach uciekają z wielu ogarniętych wojną zakątków świata, w szczególności z Kosowa, Somalii, Afganistanu, Iraku i Syrii.

Pierwsza z tych dwóch grup, Żydzi, jest idealnym przykładem uchodźców, których historia została wyidealizowana i zmitologizowana i w takiej formie istnieje w świadomości Brytyjczyków, dumnych z tego, że ich kraj otworzył granice dla obcokrajowców, ratując ich od Holokaustu i zapewniając im warunki życia pozwalające na integrację i rozwój. Jednak wspomnienia tamtych wydarzeń nie pokrywają się z prawdą historyczną. W rzeczywistości Żydzi nie wzbudzili zbyt wiele współczucia wśród mieszkańców Wysp, a ich przybycie spotkało się z głośnymi protestami i wrogością, okazywaną przez Brytyjczyków wobec tych, którzy postanowili osiedlić się w Wielkiej Brytanii na stałe.

Podobnie jak dzisiejszy napływ muzułmanów prowadzi do powstawania masowych ruchów ksenofobicznych, takich jak English Defence League, również wzrost liczby żydowskich uchodźców pod koniec XIX wieku doprowadził do pojawienia się organizacji zwanej British Brothers League, przyciągającej tysiące zwolenników na marsze i spotkania, którym niekiedy towarzyszyły akty przemocy. Tak jak dzisiejsi protestujący przeciwko muzułmanom, członkami Ligi byli głównie mężczyźni z klasy robotniczej, zamieszkujący tereny, w których wysoki odsetek mieszkańców stanowili imigranci. Ludzie ci czuli, że przybysze zagrażają gospodarce i kulturze ich kraju. Podobnie jak dzisiejsi politycy czują się w obowiązku odpowiedzieć na takie presje, próbując ogarniczyć przyjazd imigrantów, tak w roku 1905 rząd brytyjski ustanowił pierwsze w historii kraju prawo antyimigracyjne - tzw. Aliens Act - mające na celu zmniejszenie liczby przybywających Żydów ${ }^{14}$.

Przede wszystkim warto wspomnieć, że wiele osób całkowicie wyklucza możliwość porównania dzisiejszych uchodźców muzułmańskich do Żydów uciekających przed Holokaustem. Jest to szczególnie widoczne w żydowskiej prasie popularnej i prawdopodobnie wynika $\mathrm{z}$ chęci ochrony postrzeganej niepowtarzalności żydowskiego cierpienia, a szczególnie Holokaustu. Napięcia między Żydami a muzułmanami zarówno na arenie międzynarodowej, jak i lokalnej również odgrywają tu rolę, zwłaszcza zaś fakt, iż niektórzy Żydzi na Zachodzie chcą minimalizacji imigracji muzułmanów, gdyż znaczna część antysemityzmu w krajach zachodnich pochodzi ze społeczności muzułmańskich. Jak zauważa Nasar Meer, pomimo pewnych podobieństw w uprzedzeniach, których doświadczyły obie grupy, „polityczna

${ }^{14}$ G. Field (1979), Anti-Semitism with the Boots Off, w: Strauss H. (red.), Hostages of Modernization. Studies on Modern Antisemitism 1870-1993/9, Berlin: Walter de Gruyter, s. 302-303; C. Homes (1979), Anti-Semitism in British Society, 1876-1939, London: Arnold, s. 89-96, 101. 
przestrzeń dla solidarności wśród grup muzułmańskich i żydowskich jest coraz bardziej ściśnięta imperatywami geopolitycznymi”"

Przykładowo, w artykule z żydowskiego czasopisma „Tablet” czytamy, że przyrównywanie syryjskich uchodźców do Żydów uciekających przed nazistami jest "analogią w złej wierze" ${ }^{16}$. Felietonistka "Jewish Chronicle” pisze natomiast, że "muzułmanie nie są nowymi Żydami”"17. Jednakże takie stwierdzenia zazwyczaj upadają po głębszej analizie, gdyż zwykle opierają się na pewnej wyidealizowanej (i nieprawdziwej) pamięci zbiorowej, o której już wcześniej wspomniałem. Dla przykładu, pisząc w „Tablet”, James Kirchick twierdzi, że w latach 30. i 40. XX wieku „nie było uzasadnionych obaw, czy żydowscy uchodźcy (...) podzielali liberalno-demokratyczne wartości społeczeństwa amerykańskiego, czy mogli stać się podatni na radykalizację ze strony światowego ruchu terrorystycznego", a dzisiejsi muzułmańscy uchodźcy słusznie przyciągają takie podejrzenia ${ }^{18}$. Jednak w rzeczywistości uprzedzenia były w tamtym czasie poszechne w Ameryce i opierały się w dużej mierze na odczuciu, że Żydzi byli obcy i niekompatybilni, oraz na obawach, że byli oni związani z radykalnym i pełnym przemocy światowym ruchem - komunizmem. W 1939 roku 53\% Amerykanów przyznało w pewnej ankiecie, że „Żydzi są inni i powinno się ich ograniczyć" ${ }^{19}$. W tym samym roku inna ankieta wykazała, że $61 \%$ Amerykanów twierdziło, iż rząd nie powinien zezwolić 10 tysiącom żydowskich dzieci-uchodźców z nazistowskich Niemiec na wjazd do kraju ${ }^{20}$.

Również w literaturze akademickiej było zaskakująco niewiele prób porównania antysemityzmu $\mathrm{z}$ islamofobią, mimo tego, iż sondaże pokazują, że w wielu krajach występuje „niezwykle wysoka (...) korelacja pomiędzy niepochlebnymi opiniami na temat Żydów i niepochlebnymi opiniami na temat muzułmanów"21. Wśród tych badaczy, którzy ową próbę podjęli, jest wstępna gotowość, by zaakceptować

${ }^{15}$ N. Meer (2012), Racialization and religion: race, culture and difference in the study of antisemitism and Islamophobia, „Ethnic and Racial Studies”, nr 36, s. 393-394.

${ }^{16}$ J. Kirchick (2015), The Bad-Faith Analogy Between Syrian Refugees and Jews Fleeing Nazi Germany, „Tablet”, www.tabletmag.com/jewish-news-and-politics/195469/syrian-refugees-analogy [data dostępu: sierpień 2017].

17 J. Burchill (2016), Reasons why Muslims are not "the new Jews”, „The Jewish Chronicle”, www. thejc.com/comment-and-debate/comment/153626/reasons-why-muslims-are-not-new-jews [data dostępu: sierpień 2017].

${ }^{18}$ J. Kirchick, The Bad-Faith Analogy....

19 B. Van Driel (2015), Teaching about and Teaching through the Holocaust: Insights from (Social) Psychology, w: Gross Z., Doyle Stevick E. (red.), As Witnesses Fall Silent: $21^{\text {st }}$ Century Holocaust Education in Curriculum, Policy and Practice, Cham: Springer, s. 100.

${ }^{20}$ F. Newport (2015), Americans' Views on Refugees Coming to U.S., Gallup Organization, www.gallup.com/opinion/polling-matters/186716/historical-review-americans-views-refugeescoming.aspx [data dostępu: sierpień 2017].

${ }^{21}$ Pew (2008), Unfavorable Views of Jews and Muslims on the Increase in Europe, Pew Research Centre, www.pewglobal.org/2008/09/17/chapter-1-views-of-religious-groups [data dostępu: August 2017]. 
podobieństwa między uprzedzeniami, z którymi borykają się muzułmanie i Żydzi. Jak twierdzi Thomas Linehan, zarówno żydowscy, jak i muzułmańscy uchodźcy w Wielkiej Brytanii byli „kozłami ofiarnymi za bolączki związane z (...) modernizacją i kapitalistyczną globalizacją"22. Meer i Tehseen Noorani również sugerują, że w Wielkiej Brytanii można zaobserwować „znaczące podobieństwa w (...) brzmieniu antysemityzmu i uczuć antymuzułmańskich”, a także „podobne (...) dyskursywne tendencje funkcjonujące w przedstawianiu każdej mniejszości”. Podkreślają oni też znaczenie analizy tych podobieństw: „Nie zakładając żadnej dokładnej równoważności ani, co równie ważne, żadnego determinizmu w rezultacie, twierdzimy, że porównanie antysemityzmu i uczuć antymuzułmańskich mogłoby zapewnić nowe spostrzeżenia o naszym rozumieniu obu tych zjawisk"23.

\section{Dyskursy uprzedzeń: uchodźcy jako zagrożenie dla kultury, bezpieczeństwa i gospodarki narodu}

Jak wskazuje powyższe, uchodźcy żydowscy i muzułmańscy nie tylko wzbudzili wrogość w Wielkiej Brytanii, ale też ściągnęli na siebie zarzuty mające bardzo podobny charakter. W dalszej części tego artykułu postaram się przyjrzeć trzem konkretnym sferom, w których widoczne są wyraźne podobieństwa, a także pewne różnice pomiędzy tym, w jaki sposób byli postrzegani Żydzi i muzułmanie w Wielkiej Brytanii.

Po pierwsze, obydwie grupy zostały uznane za zagrożenie kulturowe. Jest to pogląd, który, jak zauważa Meer, istnieje w Anglii od XVI wieku, kiedy muzułmanów i Żydów postrzegano podobnie jako symbole „niechrześcijańskiej różnicy” ${ }^{24}$. W ciągu ostatnich lat w Wielkiej Brytanii, podobnie jak w innych krajach Europy, muzułmanie są regularnie oskarżani o wyobcowanie kulturowe, niechęć do asymilacji oraz o to, że zagrażają stylowi życia i tożsamości brytyjskiej ${ }^{25}$. Analogicznie, kiedy sto lat temu dziesiątki tysięcy ubogich Żydów przybyło z Europy Wschodniej, wprowadzając obce obrzędy kulturowe i religijne, często nie znając słowa po angielsku, zbudziły się wielkie obawy, czy wpasują się oni w społeczeństwo brytyjskie.

22 T. Linehan (2012), Comparing Antisemitism, Islamophobia and Asylophobia: The British Case, „Studies in Ethnicity and Nationalism”, nr 12, s. 383.

${ }^{23}$ N. Meer, T. Noorani (2008), A sociological comparison of anti-Semitism and anti-Muslim sentiment in Britain, „The Sociological Review”, nr 56, s. 195-196.

${ }^{24}$ N. Meer, Racialization and religion..., s. 387-388.

${ }^{25}$ M. Goodwin (2016), New British Fascism: Rise of the British National Party, Londyn: Routledge, s. 61; J. Klein (2016), The failure of Muslim integration in the UK, „Frontpage Mag”, www. frontpagemag.com/fpm/262478/failure-muslim-integration-uk-joseph-klein [data dostępu: sierpień 2017]; V. Cooper (2014), The inconvenient truth about Islamic immigration, „The Commentator”, www.thecommentator.com/article/5036/the_inconvenient_truth_about_islamic_immigration [data dostępu: sierpień 2017]. 
Ponadto Żydów widziano jako chciwych, ostentacyjnych i niemoralnych, ze skłonnościami do tworzenia hermetycznych grup, czyli jako nosicieli cech stanowiących całkowite przeciwieństwo szlachetnych brytyjskich zalet.

Takie obawy były nie tylko domeną skrajnych ekstremistów, gdyż przeniknęły do najwyższych szczebli społeczeństwa. William Joynson-Hicks, minister spraw wewnętrznych w latach 20., zaatakował „tych, którzy przedkładają swoją żydowską narodowość nad tę angielską” i bał się „Anglii (...) zalewanej wszystkimi obcymi wyrzutkami z każdego zakątka świata”" ${ }^{26}$ Gazeta "The Times” napisała, że Żydzi, „okazując odrobinę wschodniej arogancji, trzymają się z dala od mieszkańców. Patrzą na nas z podejrzliwością i swego rodzaju pogardą (...). Ci ludzie pozostają obcym elementem na naszej ziemi” "27. Poeta T.S. Eliot twierdził, że „większa liczba Żydów nie jest pożądana (...) [ponieważ] w miejscu, gdzie istnieją dwie kultury (...) obie się zacierają (...). Właśnie dlatego populacja powinna być jednolita”28.

Podobnie jak współcześni muzułmanie są oskarżani o przejmowanie całych dzielnic, zmienianie ich charakteru i sprawianie, że miejscowa ludność czuje się w nich niemile widziana ${ }^{29}$, tak samo Żydzi spotykali się ze stawianymi im podobnymi zarzutami. Jak każda grupa imigrantów, która przybywała do Wielkiej Brytanii, wielu Żydów początkowo wybierało życie w pobliżu innych członków swojej społeczności. Największa tego typu dzielnica powstała we wschodnim Londynie, gdzie niektóre ulice były zamieszkiwane wyłącznie przez Żydów, co przyczyniło się do powszechnego strachu i niechęci. Pewien znany brytyjski dziennikarz napisał, że Żydzi „rozprzestrzeniają się niczym zaraza”, co sprawia, że wschodni Londyn stał się „obozowiskiem wrogiego plemienia (...). Dla Anglika nie jest przyjemną myśl, że jego rodacy zostali wysiedleni ze swoich zabytkowych i historycznych miejsc (...) przez tę inwazję" ${ }^{30}$. Lokalny biskup skarżył się, że imigranci „zalewają całe okolice kiedyś zamieszkane przez Anglików"31.

Interesujący jest również fakt, iż ze względu na tę postrzeganą obcość, zarówno Żydzi, jak i muzułmanie musieli się zmierzyć z podobnymi presjami społecznymi, by się dostosować. Na początku XX wieku oczekiwano od „dobrych”, zasymilowanych Żydów, że pomogą swoim „złym” odpowiednikom poprawić ich zachowanie. Podobnie dziś „umiarkowanym” muzułmanom mówi się, że muszą poprowadzić walkę przeciwko „ekstremistom”" ${ }^{32}$. Kształtuje to antysemityzm i islamofobię nie

${ }^{26}$ D. Cesarani (1989), The Anti-Jewish Career of Sir William Joynson-Hicks, Cabinet Minister, „Journal of Contemporary History", nr 24, s. 461-464, 466, 472, 475.

27 Ibid., s. 471.

${ }_{28}$ T. Eliot (1934), After Strange Gods: A Primer of Modern History, Londyn: Faber \& Faber, s. 19-20.

${ }^{29}$ N. Meer, T. Noorani, A sociological comparison..., s. 207.

${ }^{30} \mathrm{H}$. Thorogood (1935), East of Aldgate, Londyn: Allen \& Unwin, s. 83-85, 132-134.

${ }^{31}$ S. Synder (2015), Moving the Anglican Communion: Ethnics and Ecclesiology in the Age of Migration, w: Chapman M., Clarke S., Percy M. (red.), The Oxford Book of Anglican Studies, Oxford: Oxford University Press, s. 562.

${ }^{32}$ N. Meer, T. Noorani, A sociological comparison..., s. 206-207. 
jako irracjonalne uprzedzenie, które musi zostać podważone wśród rodzimej populacji, ale jako obowiązek samych Żydów i muzułmanów, z wnioskiem, że oni sami będą winni, jeśli nie uda im się rozwiązać problemu. Badacze angielsko-żydowskiej historii nazywają to zjawisko „liberalnym antysemityzmem”. Jest to pogląd, że warunkiem brytyjskiej tolerancji jest zrzeczenie się przez imigrantów elementów własnej tożsamości uważanych za niekompatybilne ze spodziewanym przyjęciem angielskości. Jak ujął to Holmes, „oczekiwano, że Żydzi przestaną być żydowscy”33. Stąd w 1936 roku czołowy polityk brytyjski twierdził, że to Żydzi sami „stworzyli antyobce nastroje" i radził, żeby sami zmniejszyli antysemityzm poprzez starania o bycie „idealnie poprawnymi w swoim (...) zachowaniu” ${ }^{34}$. Osiemdziesiąt lat później, w roku 2015, minister w rządzie Davida Camerona ostrzegł brytyjskich przywódców muzułmańskich, mówiąc, że choć za islamski ekstremizm odpowiedzialna była mała grupa, która „przywłaszczyła sobie” wiarę muzułmańską, „obowiązkiem” większości muzułmanów było „wyjaśnienie i ukazanie, w jaki sposób wiara w islam może być częścią tożsamości brytyjskiej”35.

Drugą powszechną obawą, podsycaną przez przybycie Żydów i muzułmanów, było to, że stanowią oni zagrożenie dla bezpieczeństwa narodowego. Obie grupy wielokrotnie oskarżano o większe przywiązanie do swoich współwyznawców w innych krajach niż do kraju ich goszczącego. Obie też były postrzegane jako zwolennicy niebezpiecznej, brutalnej i obcej ideologii. W przypadku muzułmanów ideologią tą jest islamski ekstremizm, a z kolei dla Żydów był nią komunizm lub inne rewolucyjne doktryny ${ }^{36}$. Tak jak dziś nagłówki gazet wzmagają strach przed „muzułmańskimi ekstremistami”, sto lat temu temu doniesienia prasowe przestrzegały przed żydowskimi „anarchistami i nihilistami” ${ }^{37}$.

W obu przypadkach oskarżenia zawierają ziarno prawdy: niektórzy muzułmanie skłaniają się ku ekstremizmowi, podobnie jak wielu Żydów było członkami komunistycznych lub innych radykalnych ugrupowań ${ }^{38}$. W każdym z przypadków takie jednostki miały podobny profil: młodzi mężczyźni urodzeni w Wielkiej Brytanii

${ }^{33}$ C. Holmes, Anti-Semitism..., s. 104; B. Williams (1985), The Anti-Semitism of Tolerance: Middle-Class Manchester and the Jews 1870-1900, w: Kidd A., Roberts K. (red.), City, class and culture: Studies of social policy and cultural production in Victorian Manchester, Manchester: Manchester University Press, s. 2, 4, 94-95; T. Kushner (1990), The Impact of British Anti-semitism, 1918-1945, w: Cesarani D. (red.), The Making of Modern Anglo-Jewry, Oxford: Blackwell, s. 202.

${ }^{34}$ D. Tilles (2015), British Fascist Antisemitism and Jewish Responses, 1932-40, Londyn: Bloomsbury, s. 68 .

35 (2015), Eric Pickles' letter to Muslim leaders: the text in full, „The Independent”, www.independent.co.uk/news/uk/eric-pickles-letter-to-muslim-leaders-the-text-in-full-9987249.html [data dostępu: sierpień 2017].

${ }^{36}$ N. Meer, T. Noorani, A sociological comparison..., s. 212-213.

${ }^{37}$ D. Rosenberg (2015), UKIP is nothing new: the British Brothers' League was exploiting immigration fears in 1901, „The Guardian”, www.theguardian.com/uk-news/2015/mar/04/ukip-nigelfarage-immigrants-british-brothers-league [data dostępu: sierpień 2017].

${ }^{38}$ W. Fishman (1975), East End Jewish Radicals, Londyn: Duckworth. 
w imigranckich rodzinach, czujący się nie do końca akceptowani przez społeczeństwo brytyjskie, ale także nie do końca utożsamiający się z kulturową spuścizną swoich rodziców. To stawało się powodem poszukiwania przez nich alternatywnej tożsamości i wspólnoty, co skutkowało czasem ideologicznym ekstremizmem ${ }^{39}$.

Zarówno Żydzi, jak i muzułmanie często mieli powiązania zagraniczne: islamscy ekstremiści w Wielkiej Brytanii otrzymują wsparcie finansowe z zagranicy ${ }^{40}$, a w latach międzywojennych Związek Radziecki finansował Komunistyczną Partię Wielkiej Brytanii i inne ugrupowania rewolucyjne ${ }^{41}$. Islamscy ekstremiści dziś wyjeżdżają do Syrii, aby walczyć w wojnie domowej ${ }^{42}$, tak jak wielu lewicowych brytyjskich Żydów dołączało do walk podczas hiszpańskiej wojny domowej ${ }^{43}$. Wydarzenia w kraju i za granicą potęgują taki strach. Ataki terrorystyczne w Europie Zachodniej oraz przemoc i niepokój w krajach muzułmańskich przyczyniają się do rozbudzenia lęków przed rozprzestrzenianiem się islamskiego ekstremizmu. Podobnie sto lat temu działalność rewolucjonistów na Zachodzie i rewolucja październikowa w Rosji wywoływały obawy przed szerzeniem się komunizmu w całej Europie.

Jednak obawy zarówno przed Żydami, jak i muzułmanami są znacznie wyolbrzymione. Tylko niewielki odsetek członków obu grup podzielał takie skrajne poglądy, a większość była i jest lojalnymi, zasymilowanymi członkami społeczeństwa. Mimo to, jak zauważa Elizabeth Poole, nawet jeśli tylko mniejszość muzułmanów jest odpowiedzialna za przemoc, „kojarzone z nią negatywne zachowanie jest widziane jako wywodzące się z czegoś tkwiącego w istocie $\mathrm{w}$ ich religii, czyniąc każdego muzułmanina potencjalnym terrorystą" ${ }^{4}$. W podobny sposób fakt, iż mniejszość żydowska była nieproporcjonalnie reprezentowana w szeregach komunistów (a większość Żydów w Wielkiej Brytanii wyemigrowała z Rosji), wzbudził na Wyspach szczególną podejrzliwość wobec całej społeczności żydowskiej. Część posłów Partii Konserwatywnej głęboko wierzyła, że rewolucja październikowa była elementem żydowskiego spisku ${ }^{45}$. W roku 1905 konserwatywny tygodnik odniósł się do „komitetu Żydów (...) [którzy] ustalali międzynarodową politykę"46.

${ }^{39}$ G. Alderman (1989), Modern British Jewry, Oxford: Oxford University Press, s. 317-318; G. Alderman (1989), London Jewry and London Politics 1889-1986, Londyn: Routledge, s. 96.

${ }^{40} \mathrm{M}$. Townsend (2016), Inquiry into foreign backers of UK extremists gets green light, „The Guardian", www.theguardian.com/politics/2016/jan/17/inquiry-foreign-backers-uk-extremists [data dostępu: sierpień 2017].

${ }^{41}$ A. Thorpe (2000), The British Communist Party and Moscow, 1920-43, Manchester: Manchester University Press, s. 29, 211.

${ }^{42}$ BBC News (2016), Who are Britain's Jihadists?, BBC News, www.bbc.com/news/uk-32026985 [data dostępu: sierpień 2017].

${ }^{43}$ R. Baxell (2004), British Volunteers: The British Battalion in the International Brigades, 1936-1939 , Londyn: Routledge.

${ }^{44}$ E. Poole (2002), Reporting Islam: Media Representations of British Muslims, Londyn: I.B. Tauris, s. 4.

${ }^{45}$ D. Cesarani, The Anti-Jewish Career..., s. 466, 477.

${ }^{46}$ C. Holmes, Anti-Semitism in British Society..., s. 84. 
Jego redaktor obawiał się, że Żydzi próbowali „snuć intrygi przeciwko interesom brytyjskim i pracować dla naszych (...) wrogów" ${ }^{37}$. (Podobnie obecnie wielu obawia się, często używając wyolbrzymionych lub mylących dowodów dla poparcia tego twierdzenia, że brytyjscy muzułmanie nie tylko się nie zasymilowali, ale też aktywnie działają, wspierając wrogów państwa) ${ }^{48}$.

Teorię tę tylko wzmocniło opublikowanie „Protokołów mędrców Syjonu”, fałszywki, która miała przedstawiać rzekome plany Żydów dotyczące objęcia władzy nad światem. W 1920 roku jedna z czołowych konserwatywnych gazet brytyjskich opublikowała serię artykułów na temat „Protokołów”, które jej redaktor określił jako „mistrzowską demaskację żydowskiej polityki [wskazującą] na żądzę dominacji nad światem” ${ }^{49}$. Matthew Carr dowodzi, że współczesna koncepcja „Eurabii” - czyli „koszmarnej wizji europejskiej przyszłości skolonizowanej kulturowo i religijnie przez islam” - „ma wiele zasadniczych cech zmyślonego traktatu antysemickiego, «Protokołów mędrców Syjonu», w jej przedstawieniu europejskich muzułmanów jako instrumentów konspiracji o światowej dominacji”"50.

Później, podczas II wojny światowej, kiedy to Wielka Brytania walczyła przeciwko nazistom, dziesiątki tysięcy Żydów, posiadających niemieckie lub austriackie obywatelstwo, zostało uznanych przez brytyjski rząd za „wrogów z zewnątrz”. Wielu $\mathrm{z}$ nich zamknięto $\mathrm{w}$ obozach ${ }^{51}$. Sytuacja ta była paradoksalna, ponieważ Żydzi, którzy uciekli do Wielkiej Brytanii przed zagrożeniem ze strony nazistów, uważani byli za potencjalnych agentów III Rzeszy. Dziś podobny los spotyka syryjskich uchodźców, którzy postrzegani są jako potencjalni terroryści na usługach tzw. Państwa Islamskiego, mimo iż w rzeczywistości większość z nich ucieka przed przemocą ze strony takich właśnie grup. Neer zauważa, że podobne pytania o lojalność Żydów wobec Wielkiej Brytanii i ich ideologiczną wierność były zadawane podczas I wojny światowej (tysiące Żydów było zresztą internowanych w obozach). Jest tu wiele podobieństw do oskarżeń, z którymi od niedawna spotykają się muzułmanie ${ }^{52}$.

Warto też podkreślić, że zarówno żydowscy, jak i muzułmańscy uchodźcy byli postrzegani jako zagrożenie dla gospodarki. Kiedy pod koniec XIX wieku ubodzy Żydzi z Europy Wschodniej przybyli do Wielkiej Brytanii, obawiano się, że imigranci będą dla kraju ciężarem, ponieważ trzeba im będzie zapewnić dach nad głową, opiekę zdrowotną i inne formy wsparcia. Tak jak dzisiaj ściągających do Wielkiej Brytanii muzułmańskich uchodźców oskarża się o bycie ekonomicznymi

47 A. Julius (2010), Trials of the Diaspora: A History of Anti-Semitism in England, Oxford: Oxford University Press, s. 287.

${ }^{48}$ J. Melley (2015), Do 20\% of British Muslims really sympathise with jihadists?, BBC News, www.bbc.com/news/magazine-34967994 [data dostępu: sierpień 2017].

${ }^{49}$ G. Lebzelter (1978), Political Anti-Semitism in England 1918-1939, Londyn: Macmillan, s. 22.

${ }^{50}$ M. Carr (2011), The Moriscos: A Lesson from History?, „Arches Quarterly”, nr 4, s. 14; M. Carr (2006), You are now entering Eurabia, „Race and Class”, nr 48, s. 1-22.

${ }^{51}$ L. London, Whitehall and the Jews... s. 170-171.

52 N. Meer, Racialization and religion..., s. 391. 
imigrantami, którzy nadużywają brytyjskiej gościnności, podobnie w XIX wieku jeden z czołowych brytyjskich dziennikarzy twierdził, że Żydzi przybywali do Wielkiej Brytanii „nie z powodu prześladowań, ale dlatego, że chcieli naszych pieniędzy" ${ }^{53}$. Zarówno Żydzi, jak i muzułmanie zostali uznani przez brytyjską klasę robotniczą za niechcianych ekonomicznych konkurentów, zabierających miejsca pracy lub klientów, którzy w przeciwnym razie przypadaliby miejscowym robotnikom i przedsiębiorcom ${ }^{54}$.

Jednakże istotne jest dostrzeżenie jednej znaczącej różnicy pomiędzy tymi dwoma grupami. Oprócz obaw dotyczących biednych Żydów było także wiele ataków na zamożnych Żydów, których oskarżono o zdominowanie brytyjskiej ekonomii i wykorzystywanie Brytyjczyków do swoich własnych celów majątkowych. Gazeta ze wschodniego Londynu ostrzegała, że „berłem finansów Żyd (...) wykuwa okowy, którymi przygotowuje się do obciążenia tych biednych gojów". Pewien parlamentarzysta martwił się „,wzrostem znaczenia (...) tego uzdolnionego azjatyckiego plemienia (...), które czyni walkę o przetrwanie trudniejszą dla skromniej wyposażonych Anglików" "55. Takie przekonania często stawały się częścią teorii spiskowych, z oskarżeniami wysuwanymi przeciw Żydom, którzy mieli używać swoich majątków do kontrolowania polityki krajowej, a także być częścią międzynarodowego spisku. Oskarżenia te nie ograniczają się do skrajnych ekstremistów. Wybitny ekonomista J.A. Hobson napisał, że „polityka opierająca się na przekupstwie jest kontrolowana przez niewielkie międzynarodowe grono [żydowskich] finansistów” ${ }^{56}$. Jedna z popularnych gazet twierdziła $z$ kolei, że "ponura postać Żyda-finansisty stopniowo wplątuje świat w znoje sieci pieniędzy".

Obawy związane z potęgą i bogactwem Żydów nigdy nie były wyrażane wobec muzułmanów. Nawet gdy łączy się muzułmanów z jakąś konspiracją, taką jak idea „Eurabii”, są oni widziani jako pionki w spisku kontrolowanym przez inne, potężniejsze siły (takie jak Żydzi). Jak zauważają Meer i Noorani, podczas gdy Żydów często obawiano się ze względu na ich rzekome „używanie ukrytej siły (...), muzułmanów uważa się za problematycznych dokładnie dlatego, że są publicznie asertywni, a zatem działają agresywnie" ${ }^{\prime 5}$.

Choć żadne dwa przykłady nigdy nie są dokładnie takie same, takie różnice nie powinny powstrzymywać przed dostrzeżeniem podobieństw między dwoma przypadkami i wyciągnięciem $\mathrm{z}$ nich wniosków. W tym przypadku bardzo podobne reakcje na uchodźców żydowskich i muzułmańskich, mimo dzielących ich stu lat,

${ }^{53}$ D. Glover (2012), Literature, Immigration and Diaspora in Fin-de-Siècle England: A Culture History of the 1905 Aliens Act, Cambridge: Cambridge University Press, s. 117.

${ }_{54}$ W. Evans-Gordon (1903), The Alien Immigrant, Londyn: Heinemann, s. 247-248, 276-294.

55 C. Holmes, Anti-Semitism in British Society..., s. 65, 75.

${ }^{56}$ J. Hobson (1900), The War in South Africa: Its Causes and Effects, Londyn: Nisbet, s. 190$-191,196$.

${ }^{57}$ N. Meer, T. Noorani, A sociological comparison..., s. 209. 
dostarczają kolejnych dowodów na to, iż postrzeganie przez Brytyjczyków swojej gościnności często miało niewiele wspólnego z ich rzeczywistymi postawami i czynami, zarówno w przeszłości, jak i obecnie.

\section{Bibliografia}

Alderman G. (1989), London Jewry and London Politics 1889-1986, Londyn: Routledge. Alderman G. (1989), Modern British Jewry, Oxford: Oxford University Press.

Baxell R. (2004), British Volunteers: The British Battalion in the International Brigades, 19361939, Londyn: Routledge.

BBC News (2016), Who are Britain's Jihadists?, www.bbc.com/news/uk-32026985 [data dostępu: sierpień 2017].

Burchill J. (2016), Reasons why Muslims are not "the new Jews”, „The Jewish Chronicle”, www. thejc.com/comment-and-debate/comment/153626/reasons-why-muslims-are-not-new-jews [data dostępu: sierpień 2017].

Carr M. (2006), You are now entering Eurabia, „Race and Class”, Vol. 48, Issue 1, s, 1-22.

Carr M. (2011), The Moriscos: A Lesson from History?, „Arches Quarterly”, Vol. 4, Issue 8, s. $10-17$.

Cesarani D. (1989), The Anti-Jewish Career of Sir William Joynson-Hicks, Cabinet Minister, "Journal of Contemporary History", Vol. 24, Issue 3, s. 61-82.

Cooper V. (2014), The inconvenient truth about Islamic immigration, „The Commentator”, www.thecommentator.com/article/5036/the_inconvenient_truth_about_islamic_immigration [data dostępu: sierpień 2017].

Eliot T. (1934), After Strange Gods: A Primer of Modern History, Londyn: Faber \& Faber.

Evans-Gordon W. (1903), The Alien Immigrant, Londyn: Heinemann.

Field G. (1979), Anti-Semitism with the Boots Off, w: Strauss H. (red.), Hostages of Modernization. Studies on Modern Antisemitism 1870-1993/9, Berlin: Walter de Gruyter, s. 294-325.

Fishman W. (1975), East End Jewish Radicals, Londyn: Duckworth.

Fishman W. (1992), Pride and Prejudice, „History Today”, nr 42.

Freud S. (1939), Moses and Monotheism, przeł. K. Jones, Londyn: Hogarth Press.

Glover D. (2012), Literature, Immigration and Diaspora in Fin-de-Siècle England: A Culture History of the 1905 Aliens Act, Cambridge: Cambridge University Press.

Goodwin M. (2016), New British Fascism: Rise of the British National Party, Londyn: Routledge.

Hobson J. (1900), The War in South Africa: Its Causes and Effects, Londyn: Nisbet.

Homes C. (1979), Anti-Semitism in British Society, 1876-1939, London: Arnold.

Homes C. (1985), The Myth of Fairness: Racial Violence in Britain, 1911-19, „History Today”, nr 35.

Independent (2015), Eric Pickles' letter to Muslim leaders: the text in full, „The Independent", www.independent.co.uk/news/uk/eric-pickles-letter-to-muslim-leaders-the-textin-full-9987249.html [data dostępu: sierpień 2017].

Ipsos Mori (2012), Britons are more proud of their history, NHS and army than the Royal Family, Ipsos MORI, www.ipsos-mori.com/researchpublications/researcharchive/2939/ Britons-are-more-proud-of-their-history-NHS-and-army-than-the-Royal-Family-aspx [data dostępu: sierpień 2017].

Julius A. (2010), Trials of the Diaspora: A History of Anti-Semitism in England, Oxford: Oxford University Press. 
Karpf A. (2002), We've been here before, „The Guardian”, www.theguardian.com/uk/2002/ jun/08/immigration.immigrationandpublicservices [data dostępu: sierpień 2017].

Kirchick J. (2015), The Bad-Faith Analogy Between Syrian Refugees and Jews Fleeing Nazi Germany, „Tablet”, www.tabletmag.com/jewish-news-and-politics/195469/syrian-refugees-analogy [data dostępu: sierpień 2017].

Klein J. (2016), The failure of Muslim integration in the UK, „Frontpage Mag”, www.frontpagemag.com/fpm/262478/failure-muslim-integration-uk-joseph-klein [data dostępu: sierpień 2017].

Kushner T. (1990), The Impact of British Anti-semitism, 1918-1945, w: Cesarani D. (red.), The Making of Modern Anglo-Jewry, Oxford: Blackwell, s. 191-208.

Kushner T., Knox K. (1999), Refugees in an Age of Genocide: Global, National and Local Perspectives During the Twentieth Century, Londyn: Routledge.

Lebzelter G. (1978), Political Anti-Semitism in England 1918-1939, Londyn: Macmillan.

Linehan T. (2012), Comparing Antisemitism, Islamophobia and Asylophobia: The British Case, „Studies in Ethnicity and Nationalism”, Vol. 12, Issue 2, s. 366-386.

London L. (2000), Whitehall and the Jews, 1933-1948: British Immigration Policy and the Holocaust, Londyn: Cambridge University Press.

Meer N, Noorani T. (2008), A sociological comparison of anti-Semitism and anti-Muslim sentiment in Britain, „The Sociological Review”, Vol. 56, Issue 2, s. 195-219.

Meer N. (2012), Racialization and religion: race, culture and difference in the study of antisemitism and Islamophobia, „Ethnic and Racial Studies”, Vol. 36, Issue 3, s. 385-398.

Melley J. (2015), Do 20\% of British Muslims really sympathise with jihadists?, BBC News, www. bbc.com/news/magazine-34967994 [data dostępu: sierpień 2017].

Newport F. (2015), Americans' Views on Refugees Coming to U.S., Gallup Organization, www. gallup.com/opinion/polling-matters/186716/historical-review-americans-views-refugeescoming.aspx [data dostępu: sierpień 2017].

Orwell G. (1941), England Your England, w: Orwell G., The Lion and the Unicorn: Socialism and the English Genius, Londyn: Secker \& Warburg.

Panayi P. (2010), An Immigration History of Modern Britain: Multicultural Racism Since 1800, Londyn: Routledge.

Pew (2008), Unfavorable Views of Jews and Muslims on the Increase in Europe, Pew Research Centre, www.pewglobal.org/2008/09/17/chapter-1-views-of-religious-groups [data dostępu: August 2017].

Poole E. (2002), Reporting Islam: Media Representations of British Muslims, Londyn: I.B. Tauris.

Porter B. (2013), Why the new British citizenship test distorts history, „The Guardian”, www. theguardian.com/culture/2013/jan/30/british-citizenship-test-distorts-history history [data dostępu: sierpień 2017].

Refugee Council (2010), Party leaders agree on importance of refugee protection, Refugee Council, www.refugeecouncil.org.uk/latest/news/837_party_leaders_agree_on_importance_of_refugee_protection [data dostępu: sierpień 2017].

Rosenberg D. (2015), UKIP is nothing new: the British Brothers' League was exploiting immigration fears in 1901, „The Guardian”, www.theguardian.com/uk-news/2015/mar/04/ukipnigel-farage-immigrants-british-brothers-league [data dostępu: sierpień 2017].

Synder S. (2015), Moving the Anglican Communion: Ethnics and Ecclesiology in the Age of Migration, w: Chapman M., Clarke S., Percy M. (red.), The Oxford Book of Anglican Studies, Oxford: Oxford University Press, s. 559-576.

Thorogood H. (1935), East of Aldgate, Londyn: Allen \& Unwin. 
Thorpe A. (2000), The British Communist Party and Moscow, 1920-43, Manchester: Manchester University Press.

Townsend M. (2016), Inquiry into foreign backers of UK extremists gets green light, „The Guardian", www.theguardian.com/politics/2016/jan/17/inquiry-foreign-backers-uk-extremists [data dostępu: sierpień 2017].

Tilles D. (2015), British Fascist Antisemitism and Jewish Responses, 1932-40, Londyn: Bloomsbury.

Van Driel B. (2015), Teaching about and Teaching through the Holocaust: Insights from (Social) Psychology, w: Gross Z., Doyle Stevick E. (red.), As Witnesses Fall Silent: $21^{\text {st }}$ Century Holocaust Education in Curriculum, Policy and Practice, Cham: Springer, s. 95-107.

Williams B. (1985), The Anti-Semitism of Tolerance: Middle-Class Manchester and the Jews 1870-1900, w: Kidd A., Roberts K. (red.), City, class and culture: Studies of social policy and cultural production in Victorian Manchester, Manchester: Manchester University Press, s. 74-102. 